\title{
O sistema brasileiro de J ustiça: experiência recente e futuros desafios
}

\author{
JOSÉ EDUARDO FARIA
}

$\mathrm{N}$ U NCA, N A H IST Ó RI A republicana do País, juiízes e promotores alcançaram tanta evidência como agora. Graças às prerrogativas concedidas pela Constituição de 1988, as duas corporações estão presentes na vida econômica. influenciando a agenda política. E exercendo enorme protagonismo social, seja ao assegurar a proteção de interesses difusos, seja intervindo em questões relativas à justiça distributiva. $M$ as, a quem cabe a titularidade da independência funcional conquistada pelo M inistério Público (M P): à instituição como um todo ou a cada um de seus integrantes? D o lado do J udiciário, como pode almejar o direito à última palavra um Poder que controla de modo quase total o acesso aos seus quadros? E m suma, qual a legitimidade das duas instituições que compõem o "sistema de J ustiça" brasileiro, em cujo âmbito os valores da independência e da autonomia se sobrepõem a outros com os quais deveriam compor, como os da eficiência administrativa, transparência decisória e equilíbrio das finanças públicas?

Q uestões como essas ganharam importância desde que promotores e procuradores da R epública passaram a recorrer a gravações clandestinas e escutas ilegais, com o objetivo de formular denúncias criminais contra dirigentes do Executivo e do L egislativo, e magistrados passaram a se opor às "reformas estruturais", especialmente a previdenciária, e a impedir as tentativas de revogação de direitos adquiridos do funcional ismo e taxação dos inativos, em nome dos princípios do equilíbrio e da responsabilidade fiscal.

Perante a opinião pública, o Judiciário tem sido visto como um moroso e inepto prestador de um serviço público. No Executivo, os responsáveis pelo 0 rçamento Geral da U nião o encaram como um aparato com baixa eficiência gerencial e insensível ao equilíbrio das finanças públicas, pois seus gastos com obras de discutível utilidade, suas crescentes despesas de custeio e suas sentenças comprometeriam as políticas de ajuste fiscal, poriam em risco a estabilidade monetária e travariam as reformas estruturais. Além disso, juntamente com 0 M P, o J udiciário é acusado pelo Congresso de exorbitar em suas prerrogativas, interferir no processo legislativo e bloquear políticas formuladas por órgãos representativos eleitos democraticamente, "destecnificando" a aplicação da lei e, por conseqüência, levando à "judicialização" da vida administrativa e econômica.

$M$ uitas dessas críticas talvez sejam injustas. $M$ as não quer dizer que não tenham algum fundo de verdade, o que alimenta diferentes indagações sobre 0 futuro das duas instituições num contexto marcado por fortes desigualdades 
sociais e culturais, graves limitações fiscais e transformações radicais nos modos de funcionamento da economia. D ecorre daí o objetivo deste texto:

- apontar o descompasso entre a concepção arquitetônica dos tribunais e do M P e a realidade socioeconômica em que atuam;

- discutir a "judicialização" da vida política e econômica, mostrando como o crescente protagonismo de juízes e promotores numa sociedade desigual e iníqua tornaram o "sistema de J ustiça" vulnerável a tentativas de intervenções externas, justificadas sob os mais variados pretextos - da desburocratização ao combate à corrupção, da racionalização jurisprudencial à imposição do controle externo;

- avaliar as transformações qualitativas no direito positivo provocadas pela integração transnacional dos mercados de insumos, bens, serviços e capitais sobre o "sistema de J ustiça" , levando à ruptura da exclusividade do J udiciário e do MP na resolução dos conflitos.

\section{O “sistema de J ustiça” no B rasil contemporâneo}

N uma primeira aproximação, a crise do "sistema de J ustiça" se traduz pela ineficiência com que vem desempen hado suas três funções básicas: a instrumental, a política e a simbólica (Santos et al.,1996). Pela primeira, o Judiciário e o M P são o principal loci de resolução dos conflitos. Pela segunda, exercem um papel decisivo como mecanismo de controle social, fazendo cumprir direitos e o brigações contratuais, reforçando as estruturas vigentes de po der e assegurando a integração da sociedade. Pela terceira, disseminam um sentido de eqüidade e justiça na vida social, socializam as expectativas dos atores na interpretação da ordem jurídica e calibram os padrões vigentes de legitimidade na vida política.

A ineficiência do "sistema de Justiça" no exercício dessas funções decorre, em grande parte, da incompatibilidade estrutural entre sua arquitetura e a realidade socioeconômica sobrea qual tem de atuar. Em termoshi sóricos desde seus primórdios no Brasil colonial, como instituição de feições inquisitórias forjada pelo Estado português a partir das raízes culturais da Contra-R eforma, com seus prazos, instâncias e recursos, o Judiciário sempre foi organizado como um burocratizado sistema de procedimentos escritos. Em termos funcionais, foi concebido para exercer as funções instrumentais, políticas e simbólicas no âmbito de uma sociedade postulada como sendo estável, com níveis eqüitativos de distribuição de renda e um sistema legal integrado por normas padronizadoras e unívocas. O s conflitos jurídicos, nesse sentido, seriam basicamente interindividuais e surgiriam a partir de interesses unitários, mas encarados em perspectiva diametralmente oposta pelas partes. D esse modo, a intervenção judicial ocorreria após a violação de um direito substantivo e sua iniciativa ficaria a cargo dos lesados. A litigância judicial versaria sobre eventos passados. As ações judiciais seriam um processo em grande parte controlado pelas partes, a quem caberia a responsabilidade de definir as principais questões submetidas a juízo. E o alcance do julgamento ficaria circunscrito só a elas. 
Contudo, a realidade brasileira é incompatível com esse modelo de "J ustiça". I níqua e conflitiva, ela se caracteriza por situações de miséria que negam o princípio da igualdade formal perante a lei, impedem o acesso de parcelas significativas da população aos tribunais e comprometem a efetividade dos direitos fundamentais; pelo aumento do desemprego aberto e oculto; por uma violência e criminalidade urbanas desafiadoras da ordem democrática e oriundas dos setores sociais excluídos da economia formal, para os quais a transgressão cotidiana se converteu na única possibilidade de sobrevivência; por uma apropriação perversa dos recursos públicos, submetendo deserdados de toda sorte a condições hobbesianas de vida; e por um sistema legal incoerente, fragmentário e incapaz de gerar previsibilidade das expectativas, dada a profusão de leis editadas para dar conta de casos específicos e conjunturais e de normas excessivamente singelas para situações altamente complexas.

Por isso, desde que um amplo espectro de movimentos sociais emergiu entre os anos de 1970 e 1980 procurando ampliar o acesso dos segmentos marginalizados da população ao M P e à J ustiça, o advento da Constituição de 1988 propiciou um sem número de demandas judiciais para o reconhecimento de novos direitos (moradia) e a aplicação de direitos já consagrados (reforma agrária), os tribunais brasileiros passaram a protocolar, carimbar, distribuir ejulgar milhões de ações. M as, apesar dessa explosão de litigiosidade, ou por causa dela, eles jamais conseguiram conduzir os processos a uma solução definitiva e coerente com outras ações idênticas, dentro de prazos de tempo razoáveis.

A conversão dos cartórios judiciais em máquinas kafkianas de fazer transcrições e expedir notificações transforma juízes em gestores de escritórios emperrados. A atuação formalista dos tribunais superiores, ao prender-se a minúcias processuais na avaliação dos julgamentos das instâncias inferiores, retarda as decisões terminativas e/ ou desloca o foco do julgamento das questões essenciais para questões meramente procedimentais (entre 1990 e 1994, 23,18\% dos casos decididos pelo Supremo Tribunal Federal trataram exclusivamente de técnicas processuais e em $36,37 \%$ a corte empregou argumentos de direito processual como fundamentação de suas sentenças) (C astro, 1996). Por fim, a conversão dos recursos judiciais num sistema quase automático e repleto de tecnicalidades de discutível utilidade, faz da atividade-fim de juízes e promotores um trabalho de Sísifo, reduzindo as instâncias superiores ao papel de juntas administrativas de confirmação de decisões já anteriormente tomadas em casos idênticos (entre 1991 e 1996, 84\% dos recursos extrao rdinários e agravos de instrumento julgados pelo Supremo Tribunal Federal foram repetições de casos já decididos pela corte) (A rantese Kerche,1999). E, na medida em que esse contexto organizacional tende a embotar o espírito e a não estimular a reflexão e a criatividade, o Judiciário e 0 M P acabam sendo indigentes na produção de respostas para seus problemas.

Como podem eles sobreviver fechados em si mesmos, incapazes de se autoavaliar? D e que modo exercer suas funções instrumentais, políticas e simbólicas 
de modo minimamente eficiente? Como lidar com os conflitos emergentes no âmbito de uma sociedade heterogênea e complexa se o arcabouço do sistema jurídico está superado? C omo aplicar direitos que conferem prioridade aos valores da igual dade e da dignidade se a cultura profissional dos operadores jurídicos, de caráter privatista e normativista, foi forjada com base em premissas incompatíveis com a realidade socioeconômica? Como traduzir o interesse público em situações concretas, nas quais estão em choque interesses e direitos difusos, por um lado, e o direito à propriedade privada, por outro? Se as regras processuais foram concebidas basicamente para filtrar, canalizar e viabilizar a tramitação de litígios interinviduais, como os tribunais devem tratar conflitos comunitários, grupais e classistas? D e que modo desestimular o uso abusivo dos recursos, especialmente os impetrados com fins dilatórios, fator responsável pela banalização dos tribunais superiores? Se as decisões dos juízes se circunscrevem apenas aos autos e às partes, como devem agir quando a resolução dos litígios a eles submetidos implica políticas públicas, cuja responsabilidade é do Executivo? Como suas sentenças podem guardar de coerência entre si, uma vez que a inflacionada e fragmentária ordem legal não permite decisões unívocas e o sistema descentralizado de decisões judiciais carece de articulação entre suas diferentes instâncias e braços especializados? C omo proceder quando os demais poderes batem à porta dos tribunais solicitando decisões que não foram capazes de tomar consensualmente?

\section{A “judicialização" da política e da economia}

Essas questões dão a medida da crise do "sistema de Justiça". Como os complexos mecanismos processuais não permitem filtragem correta, tramitação objetiva e encaminhamento adequado dos litígios judiciais, muitas vezes eles chegam em estado bruto à apreciação dos juízes e promotores. D aí as crescentes dificuldades enfrentadas para expedir despachos e sentenças coerentes, previsíveis e oportunos, assegurando obediência às leis, garantindo o cumprimento dos contratose, com isso, dando aos atores sociais e aos agentes econômicoso ambiente, as condições e os estímulos para a tomada de decisões racionais.

C omo a magistratura não pode deixar sem resposta os casos que lhes são submetidos, independentemente de sua complexidade técnica e de suas implicações econômicas, políticas e sociais, ela se sente impelida a exercer uma criatividade decisória que acaba transcendendo os limites da própria ordem legal. Afinal, em casos difíceis, nos quais a interpretação a ser dada a uma norma, lei ou código não está clara ou é controvertida, "os juízes não têm outra opção a não ser inovar, usando o próprio julgamento político" (D workin, 1997). O problema éque, em muitos desses casos, nos quais julgar não significa apenas estabelecer o certo ou o errado com base na lei, mas também assegurar a concretização dos objetivos substantivos por ela previstos, o J udiciário e o M P não dispõem de meios próprios para implementar suas sentenças e pareceres, especialmente as que pressupõem decisões, recursos materiais e investimentos do setor público. À mercê de gastos, 
programas governamentais e serviços públicos fora de sua competência e jurisdição, o "sistema de Justiça" encontra se numa encruzilhada.

Por um lado, quando insiste em enquadrar o Executivo, para obrigá-lo a oferecer esses serviços num contexto de "responsabilidade" fiscal, cortes de orçamento e ausência de fontes permanentes de recursos para o financiamento de políticas públicas, bem como promover o controle da constitucionalidade das leis e obrigar as autoridades econômicas a circunscrever suas decisões aos estritos limites da ordem legal, a Justiça e o M P são sempre acusados de abandonar 0 "princípio da neutralidade" e de "fazer política", exorbitando suas funções e invadindo áreas que não são de sua alçada. Como conseqüência, são ameaçados de retaliações e são objeto de críticas desqualificadoras, por não compreender a racionalidade sistêmica da economia - "incompreensão" essa cada vez maisutilizada pelo Executivo como pretexto para impor obstáculos ao exame e controle da legalidade de suas próprias decisões e atos.

Quanto menor a etabilidade macroeconômica, maior a crise de governabilidade- esse seria, segundo os governantes, o efeito o que o "idealismo formalista" da magistratura osimpediria de neutralizar. Quantomaior a di scricionariedade dosgovernantes menor a cer teza jurídica - esse seria, segundo juízes e promotores, o efeito corrosivo de uma "razão econômica" que, situada fora do domínio das determinações jurídicas e deixada sem efetivo controle constitucional, conduziria à progressiva erosão do Estado de Direito. $\mathrm{N}$ ão foi por coincidência que, na dinâmica desse embate entre juízes e promotores "desatentos" às conseqüências macroeconômicas de suas decisões e economistas que freqüentemente desconhecem os fundamentos jurídicos que alicerçam suas estratégias de desenvolvimento, passaram a ganhar corpo as propostas de criação do controle externo sobre a magistratura, de ampliação do número de mecanismos processuais de proteção antecipada do Executivo contra demandas que os cidadãos possam ajuizar contra ele (como a ação declaratória de constitucionalidade e o incidente de constitucionalidade) e de imposição da súmula vinculante. M as isso só ocorreu depois que parte da corporação judicial começou a pressionar diferentes setores da administração pública com o objetivo de criar as condições necessárias para a implementação dos direitos econômicos e sociais assegurados pela Constituição de 1988; ou, então, a interpretá-la em perspectiva oposta aos interesses dos responsáveis pelas políticas de "ajuste fiscal" e estabilização monetária no âmbito do Executivo; ou, ainda, a tomar decisões com enormes custos para a "governabilidade", como nas ações relativas à criação de novos tributos, desindexação de salários, privatização de empresas públicas etc.

Por outro lado, para neutralizar o risco de retaliações, o "sistema de J ustiça" tem a alternativa de agir pragmaticamente, deixando de confrontar o Executivo e tolerando sua tendência em invocar os imperativos da responsabilidade fiscal e da estabilidade monetária como justificativa para legislar para situações pretéritas, revogar atos juridicamente perfeitos e interferir em direitos adquiridos. 0 s tribu- 
nais e o M P também podem recorrer a critérios de "justiça comutativa" ao apreciar e julgar as ações judiciais resultantes do despertar de determinados setores sociais para o reconhecimento de seus direitos de cidadania. Elestambém podem limitar suas iniciativas "modernizadoras" à descentralização administrativa, à demanda por investimentos em informática e instalações físicas e à mobilização por um aumento de recursos para a expansão do número de varas e juízes, mantendo-se apegados a doutrinas jurídicas que o distanciam da eficiência operacional e da justiça social. E ainda têm a possibilidade de continuar insistindo na expansão dos juizados especiais para pequenos conflitos de massa, que libera os tribunais para a resolução de conflitos de maior valor, gravidade e complexidade técnico-jurídica. Essa é uma experiência bem-sucedida de simplificação das formas processuais no âmbito da justiça comutativa, ainda que o tempo da execução das decisões seja inversamente proporcional ao tempo do julgamento. $M$ as, além de limitar a efetividade de garantias constitucionais, especialmente no âmbito penal, ela não funciona nos conflitos e controvérsias que envolvem direitos sociais e questões distributivas.

Com estratégias como essas, o Judiciário poderia levar seus integrantes a assumir a perspectiva de juízes executores (com baixa autonomia decisória e baixa criatividade judicial) ou, no máximo, de juízes del egados (com alta criatividade, mas escassa autonomia decisória) (Guarnieri, 1996), conseguindo assim preservar a indepen dência da instituição frente aos demais poderes. $M$ as, a eficácia da tutela judicial fica em parte comprometida, levando o "sistema de J ustiça" a dois riscos: o de se tornar social mente irrelevante e ver aumentar os níveis de descrédito com que a maioria das instituições brasileiras é encarada pela população e o de ver ainda ampliado o número de pessoas - cerca de $69,7 \%$ da população - envolvidas em algum tipo de conflito que não levou ou não pôde levá-los a um tribunal e das quais 43\% o resolveram por conta própria (Santos, 1993).

Sempre descrito de modo simplista pela mídia, a "judicialização" da política e da economia é um fenômeno complexo, que envolve diferentes fatores. U m é a incapacidade do Estado de controlar e regular, com os instrumentos normativos de um ordenamento jurídico resultante de um sistema romano, rígido e sem vínculos com a realidade contemporânea, mercados cada vez mais integrados em escala planetária. Pressionado por fatores conjunturais, enfrentando contingências que desafiam sua autoridade, condicionado por correlações circunstanciais de forças, obrigado a exercer funções muitas vezes incongruentes entre si elevado a tomar decisões em contradição com os interesses sociais vertidos em normas constitucionais, o Estado tende a legislar desenfreadamente com o objetivo de coordenar, limitar e induzir o comportamento dos agentes produtivos. Essa legislação, contudo, não só é quase sempre produzida ao arrepio da Constituição, como também costuma fundir diferentes matérias num mesmo texto legal ou fragmentar a mesma matéria em diferentes decretos, leis, medidas provisórias etc. Com seus quinze anos de vigência, a Constituição de 1988 já é mais emendada das que o B rasil já teve. $\mathrm{N}$ o âmbito tributário, onde a média é de trezentas novas 
normas por ano, essa legislação se desdobra em 55.767 artigose 33.374 parágrafos (O Estado deS. Paulo, 8/ 8/ 2001).

0 resultado dessa estratégia legislativa é paradoxal. Q uanto mais o Estado recorre a ela quer para regular e controlar o funcionamento da economia, quer para neutralizar as contingências advindas do jogo de mercado, menos vê suas metas concretizadas e suas decisões acatadas. Q uanto mais normas edita para resolver problemas específicos e pontuais, mais o Estado os multiplica, pois essas normas se intercruzam e criam intricadas cadeias normativas, rompen do a unidade lógica, a coerência conceitual, a uniformidade doutrinária e a funcionalidade do próprio ordenadamente jurídico. Deste modo, em vez de propiciar certeza e aumentar o potencial de eficácia da legislação, pois todo caso bem-sucedido de aplicação das leis e de solução de controvérsias sempre acarreta efeitos de demonstração que fortalecem a confiança no sistema jurídico, ele produz o inverso.

0 mesmo Estado que legisla desenfreadamente para estabilizar a moeda e acabar com a inflação econômica acaba provocando instabilidade legal e inflação jurídica. Com isso, ele não só acirra os conflitos, encurta seu próprio horizonte decisório e compromete suas políticas, como também dificulta o cálculo racional entre os agentes produtivos, distorce a formação dos preços relativos, dissemina insegurança no sistema econômico e multiplica as tensões no âmbito tanto do L egislativo como do J udiciário e do M P. N o primeiro poder, as tensões decorrem do fato de que ele é levado a funcionar não em função da lógica e dos valores inerentes à representação política, mas, antes, das necessidades conjunturais e do tempo decisório do Executivo. No segundo, as tensões decorrem do fato de que o cipoal normativo leva os tribunais superiores a serem chamados para tentar restabelecer ou assegurar um mínimo de coerência e unidade no sistema jurídico.

É aí que surge o fenômeno da "judicialização" - a crescente ampliação da ação executiva e legislativa dos tribunais na vida política e econômica (Tate e Torbjörn, 1997). Como a ordem jurídica assim produzida não oferece aos operadores do direito as condições para que possam extrair de suas normas critérios constantes e precisos de interpretação, ela exige um trabal ho interpretativo contínuo. E como seu sentido definitivo só pode ser estabelecido quando de sua aplicação num caso concreto, na prática os juízes são obrigados a assumir um poder legislativo. O u seja, ao aplicar as leis a casos concretos, eles terminam sendo seus coautores. Por isso, a tradicional divisão do trabalho jurídico no Estado de D ireito é rompida pela incapacidade do Executivo e do L egislativo de formular leis claras e sem lacunas, de respeitar os princípios gerais de direito e de incorporar as inovações legais exigidas pela crescente integração dos mercados. I sso propicia o aumento das possibilidades de escolha, decisão e controle oferecidas à promotoria eà magistratura, levando assim ao protagonismo judicial na política e da economia. $E$, na medida em que 0 "sistema de Justiça" tem de decidir questões legais de curto prazo e com enormes implicações socioeconômicas, ele se converte numa instituição "legislativamente" ativa). 
Essas dificuldades do Executivo e do L egislativo e a "judicialização" da política e da economia daí advindas não são fato novo no Brasil. Elas começaram a aparecer quando o legislador dos anos de 1980, ao modernizar a legislação processual com o objetivo de ampliar o alcance da tutela judicial para proteger os direitos difusos, passou a delegar competências para a magistratura, aumentando seus poderes cautelares, expandindo suas prerrogativas em matéria de apreciação de provas etc. E se tornaram visíveis na Assembléia Constituinte, quando seus integrantes optaram por redigir uma C arta com "textura aberta" e normas programáticas nas matérias polêmicas, por causa da ausência de bancadas hegemônicas, capazes de propiciar um tratamento jurídico objetivo. Como nenhum partido dispunha, por si ou sob a forma de coalizões, de maioria qualificada para agir na conformidade de um projeto político capaz de dar um mínimo de unidade conceitual e coerência programática à nova ordem constitucional, o recurso a normas programáticas e cláusulas indeterminadas, que poderiam ser reguladas posteriormente por leis complementares e ordinárias, em outras condições e outras configurações partidárias, foi a estratégia adotada para permitir a conclusão dos trabalhos.

Por isso, o texto constitucional ficou ambíguo e sem espírito definido, sendo impossível saber ao certo em várias matérias o que de fato é direito adquirido, o que pode ser objeto de emenda e o que foi convertido em cláusula pétrea. A Constituição se desdobra em inúmeros capítulos, artigos e incisos que, se por um lado expressam o precário equilíbrio entre as diferentes forças políticas no âmbito da Assembléia Constituinte, por outro congelam determinadas situações sociais e econômicas sem explicar como podem ser mantidas, em termos materiais. Com isso, o "sistema de J ustiça" teve sua discricionariedade ampliada na dinâmica do processo de redemocratização do País, sendo levado a assumir o papel de legitimador, legislador e até de instância recursal das próprias decisões do sistema político, formado pelo Executivo e pelo Legislativo.

Em princípio, o sistema político pode adiar suas decisões à espera de melhor oportunidade para agir, encarando a própria Constituição como fórmula relativamente maleável de tomada de decisões coletivas. 0 mesmo não acontece com os tribunais e o M P. Por sua natureza, estrutura e função, eles não podem deixar de decidir quando acionados pela sociedade, mesmo que as normas a serem aplicadas tenham uma textura aberta, sejam indeterminadas, antinômicas ou lacunosas. Para o "sistema de J ustiça", suas decisões são formuladas com base nas premissas oferecidas pelo sistema político, sob a forma de normas, leis e códigos. E se essas premissas não são claras, precisas e coerentes, pois a produção legislativa do Executivo é cada vez mais condicionada por suas respostas contingentes às mudanças econômicas e às oscilações dos mercados, os tribunais e o M P não podem ser culpados por isso, nem serem responsabilizados por problemas que, do ponto de vista substantivo, não são de sua competência. 


\section{A indiferenciação entre os sistemas político, econômico e judicial}

A indiferenciação entre os sistemas político, econômico e judicial é a questão essencial no conflito de interesses entre o Executivo e o Legislativo com o "sistema de J ustiça", desde o advento das políticas de ajuste fiscal, nos anos de 1990, com o objetivo de restabelecer o equilíbrio financeiro do Estado. Se a esfera de atuação dos tribunais cresceu a ponto de levá-los a assumir funções políticas, bloqueando iniciativas do Executivo ou justapondo-se ao L egislativo, é porque a Constituição de 1988 o permitiu, na medida em que consagrou um extenso elenco de direitos, aumentou as garantias para proteção dos direitos fundamentais e elevou as transferências de recursos da U nião para $E$ stados e municípios. N a medida em que a relação G overno-C ongresso, que é eminentemente política, ficou carente de um árbitro por causa da excessiva rigidez como a Carta disciplinou a separação dos poderes, coube ao Judiciário exercer esse papel. M as de que modo exigir dele que sua arbitragem seja exclusivamente técnica e formal? D e que modo pode a instituição conciliar a natureza política dos conflitos institucionais submetidos à sua apreciação com a necessidade de proferir decisões baseadas e circunscritas à letra da lei? (Sadek e Arantes, 1994).

O problema é que, se por um lado isso pode ser usado como "argumento de defesa" do "sistema de J ustiça" para refutar críticas e ameaças de retaliação do Executivo e do L egislativo, por outro, na dinâmica da governabilidade pós-autoritária, leva a uma superposição de esferas, critérios, procedimentos e lógicas decisórias, a uma erosão dos valores precípuos de cada um dos poderes do Estado e a uma sobrecarga no policy-making do país. Tensões institucionais e crises de governabilidade são as conseqüências mais visíveis dessa desdiferenciação entre os papéis, competências e prerrogativas do Executivo, do L egislativo e do Judiciário. A anomia jurídica, sua situação-limite.

Para neutralizar esses riscos, não cabe ao sistema judicial suprir a incapacidade decisória do Executivo ou do L egislativo, nem colocar valores como disciplina fiscal e estabilidade monetária à frente dos seus, em nome dos “interesses maiores da N ação" , como sempre reivindicaram os responsáveis pela política econômica da última década do século XX. Essa é a função básica do sistema econômico. C omo, numa sociedade complexa, o papel do sistema judicial é apenas o de aplicar a lei, seu modo operativo é binário, pois suas estruturas só estão preparadas para decidir entre o legal e o ilegal, o constitucional e o inconstitucional. 0 sistema judicial, evidentemente, não pode ser insensível ao que ocorre nos âmbitos da economia e da política. M as os tribunais e o M P só podem traduzir essa sensibilidade nos limites de sua capacidade operativa. Q uando acionados, o máximo que podem fazer é julgar se uma decisão política ou econômica é constitucional e legalmente válida. Se forem, além disso, estarão exorbitando seus papéis e justificando reaçõ es defensivas dos demais sistemas, como as já mencionadas ameaças de retaliação, sob forma de restrições orçamentárias, controle externo e súmula vinculante. 
$N$ ão é difícil identificar as conseqüências desse comprometimento da diferenciação funcional de uma sociedade complexa. 0 contra-ataque dos sistemas político e econômico ao extravasamento das funções do sistema judicial conduz, inexoravelmente, à perda de autonomia deste último (C ampilongo, 2001). Como preservá-la quando os tribunais abandonam os limites que o sistema jurídico lhes impõe? Por isso, quando a J ustiça e o M P incorporam elementos estranhos à lógica do sistema jurídico, eles não só rompem sua lógica operacional, como também politiza a aplicação do direito e leva à erosão dos marcos de referência.

Jáno âmbito do sistema social, quando tribunais e promotorias estão sobrecarregados com funções que não são suas ou se encontram em confronto com os demais poderes, a perda de rapidez, coerência e qualidade em seus serviços se converte, na prática, em sinônimo denegação de justiça - principalmente para a população de baixa renda. $\mathrm{N}$ o âmbito do sistema político, decisões judiciais lentas e incoerentes tornam-se geradoras em potencial de "crises de governabilidade". No âmbito do sistema econômico, a incapacidade judicial de confirmação de expectativas de direito torna-se um fator de insegurança no mundo dosnegócios.

N uma situação de indiferenciação generalizada entre os sistemas judicial, administrativo, político e econômico, portanto, seus efeitos podem atingir a vitalidade do regime democrático e o desenvolvimento econômico do País. N o primeiro caso, é fácil entender o motivo. Se, do ponto de vista funcional, um dos papéis da democracia é manter elevadas as possibilidades de escolha e abertas as alternativas de decisão, quando elas são reduzidas drasticamente os direitos fundamentais e as liberdades públicas ficam comprometidos. No segundo caso, o motivo também é óbvio: ordens jurídicas imprecisas na forma e contraditórias no conteúdo, aplicadas por tribunais so brecarregados, lentos e incapazes de fixar jurisprudência uniforme, sempre geram custos adicionais que são transferidos para o valor global dos empréstimos, por meio de taxas de risco.

No capitalismo, se os agentes econômicos são, por princípio, atores racionais, e seu objetivo é maximizar recursos escassos, neutral izar riscos e minimizar gastos com informações, negociações e execução de contratos, eles precisam de um quadro legal claro e preciso para poder decidir. Portanto, na dinâmica do mercado, decisões de investir ou liberar crédito têm relação direta com a objetividade e as garantias das condições de contratação das o perações financeiras e das atividades negociais - mais precisamente, com a segurança que os investidores sentem nas formas de resolução de eventuais problemas jurídicos envolvendo seus recursos ou os tomadores de empréstimos (N orth, 1990 e Pinheiro, 2000). Q uando a confiança é baixa, os resultados das transações econômicas não são previsíveis e 0 recebimento dos valores contratados é problemático, então para se proteger, os investidores adicionam ao montante do investimento um valor de risco, antecipando-se dessa maneira às dificuldades legais ejudiciais que podem enfrentar. Como o Brasil não dispõe de poupança interna suficiente para financiar seu crescimento, de que modo el e pode captar esses recursos no mercado externo se, 
por causa da imprecisão da ordem legal e da ineficácia do sistema judicial, a taxa de risco é alta?

Foi por esse motivo que o governo do PT, eleito em 2002 com base na crítica à excessiva ênfase do governo anterior ao primado da estabilidade monetária, teve de continuar defendendo reformas drásticas para "resgatar uma cultura de crédito no Brasil" e acelerar o recebimento dos valores contratados pelo sistema financeiro, mediante a redução da morosidade judicial, a diminuição dos gastos dos bancos com as áreas de avaliação de risco dos tomadores de empréstimo e a neutralização de "um sistema judiciário pró-devedor que estimula a inadimplência e inibe a atividade creditícia" (BC , 2003, p. 8). N o início de sua gestão, o governo divulgou, por meio do Banco Central, uma nota técnica afirmando que "o funcionamento deficiente do sistema judicial" leva "o bom tomador de crédito no Brasil a arcar com um custo extraordinário, independente de seu histórico de crédito e de sua capacidade de pagamento" (BC, 2003, p. 9). A nota mostra as estimativas para a recuperação de empréstimos em processos judiciais para quatro contratos hipotéticos entre $R \$ 500$ e $R \$ 50$ mil. Além das despesas processuais diretas (como custas, advogados, oficial de justiça, perícia e cartórios), os cálculos também levam em conta uma taxa de desconto intertemporal aplicada sobre o capital e arbitrada em $20 \%$ ao ano. E como os custos fixos nos processos de cobrança são altos, os empréstimos de menor valor unitário tendem a apresentar expectativa de recuperação proporcionalmente menor. A conclusão é a de que o custo de recuperação para empréstimos de até $R \$ 1.000$, se atravessadas todas as fases processuais, supera ou iguala aproximadamente o montante do principal; no caso de um crédito de $\mathrm{R} \$ 50$ mil, a expectativa de recuperação é de $24,1 \%$ do principal, se exigidas todas as fases de execução. Já a cobrança extrajudicial mais simples, que só acarreta despesas de correio, protesto e comissão paga a cobrador especializado, apresenta um valor estimado entre $56,8 \%$ e $83 \%$, nos dois extremos.

\section{O "sistema de J ustiça" e a integração dos mercados}

Essa justificativa para ampliação das garantias exigidas pelo sistema bancário tem de ser compreendida à luz da realidade econômica mundial. Com a integração dos mercados, a global ização econômica tornou os fluxos de capitais mais difíceis de serem controlados. Levou a política a ser substituída pelo mercado como instância máxima de regulação social, deixando as decisões governamentais vulneráveis a opções feitas em outros lugares sobre as quais têm escasso poder de influência e pressão. Fez com que os padrões fiscais e monetários passassem a ser determinados pela competição internacional. Esvaziou a idéia de justiça social via política tributária, convertendo os cortes de gastos sociais do Estado em instrumento disfarçado de redução de direitos. Pôs em xeque todo um sistema de garantias, proteção e oferta de condições materiais básicas conquistado democraticamente e justificado em nome da equalização de oportunidades. Transformou obrigações governamentais em negócio privado e reduziu o titular de um 
direito civil a mero consumidor de serviços empresariais, muitos dos quais prestados em mercados com baixo grau de competição e enorme desequilíbrio de forças entre ofertantese demandantes. Agravou as desigualdades socioeconômicas preexistentes e acirrou os conflitos entre os poderes locais, regionais e centrais. $E$, ao gerar formas de poder e influência novas e autônomas, colocou em questão a própria exclusividade do direito positivo.

O s tribunais e o M P não ficaram imunes a essas transformações. D esde a reestruturação do capitalismo, iniciada em resposta à crise de acumulação dos anos de 1970, eles se vêem diante de um cenário novo e incerto, no qual o Estado vem perdendo sua autonomia decisória e o ordenamento jurídico vêcomprometida tanto sua unidade quanto seu poder de programar comportamentos, escolhas e decisões. Por causa das pressões centrífugas resultantes das inovações tecnológicas, dos novos paradigmas industriais e da desterritorialização da produção, o J udiciário e o M P, com sua estrutura organizacional hierarquizada, operativamente fechada, orientada por uma lógica de caráter formal e submetida a uma rígida e linear submissão à lei, tornaram-se instituições que enfrentam o desafio de alargar os limites de sua jurisdição, modernizar suas estruturas administrativas e rever seus padrões funcionais, para sobreviver como poderes independentes.

1 - Em termos de jurisdição, como o aparato judicial foi organizado para atuar dentro de limites territoriais precisos, no contexto de exclusividade da atuação estatal, seu alcance ten de a diminuir na mesma proporção em que a expansão da informática e das comunicações permite aos atores econômicos estabelecer múltiplas redes de interação. Q uanto maior é a velocidade desse processo, mais o J udiciário é atingido pelo pluralismo regulatório e pela emergência de mecanismos menos institucionalizados de resolução de conflitos, que deslocam a procura dos tribunais para outras instâncias decisórias - as justiças emergentes nos espaços infra-estatais (as locais, com influência comunitária) e nos espaços supra-estatais (as justiças de caráter internacional e transnacional)

Todas elas variam segundo seu grau de formalidade, acessibilidade, especialização, alcance e eficácia. Atualmente, os espaços infra-estatais têm sido polarizados quer por formas' “inoficiais” ou não-oficiais de resolução de conflitos (que vão da autocomposição de interesses, sob a forma de modelos descentral izadose desprofissionalizados que estimulam a obtenção de decisões por consenso, à imposição da lei do mais forte nas favelas das grandes cidades), quer por meios solução extrajudicial de conflitos (como intervenções administrativas, autoregulação profissional, estratégias de mediação conduzidas por mediadores escolhidos pelas partes, arbitragem, comissões paritárias montadas para promover negociação coletiva em empresas etc.) (Fitzpatrick, 1988 e M oreira, 1997). Já os espaços supra-estatais têm sido polarizados pelos órgãos jurisdicionais transnacionais e pelos mecanismos adjudicatórios extrajudiciais criados por organismos multilaterais, conglomerados empresariais, instituições financeiras e entidades não-governamentais. 
2 - Em termos organizacionais, o Judiciário e o MP foram estruturados para operar sob a égide dos códigos e leis processuais cujos prazos e ritos são incompatíveis com a multiplicidade de lógicas, valores, procedimentos decisórios e horizontes temporais preval entes na economia globalizada. $\mathrm{N}$ esta, o sentido de tempo é dado por uma racionalidade de caráter material, pelo cálculo de custo/ benefício e pelas expectativas de lucro com relação a um dado ciclo de rotação dos capitais, enquanto nos tribunais e no M P ele é associado ao garantismo processual e forjado como instrumento de organização social e controle da dinâmica dos processos judiciais.

No âmbito do direito positivo, o tempo do processo judicial é o tempo diferido, encarado como sinônimo de segurança e concebido como uma relação de ordem e autoridade, representada pela possibilidade de esgotamento de todos os recursos e procedimentos numa ação judicial. Cada parte, intervindo no momento certo, pode apresentar seus argumentos e ter a garantia de ser ouvida na defesa de seus interesses. 0 tempo diferido é utilizado como instrumento de certeza, na medida em que impede a real ização de julgamentos precipitados, sem 0 devido distanciamento com relação aos acontecimentos que deram margem à ação judicial. 0 tempo da economia globalizada é o tempo real, o tempo da simultaneidade. À medida que se torna mais complexa, gerando novas contingências e incertezas, a economia globalizada obriga os agentes a desenvolver novos mecanismos para proteger negócios, capitais e investimentos da imprevisibilidade e do indeterminado. A presteza se converte numa das condições para a neutralização dos riscos inerentes às tensões e desequilíbrios dos mercados, levando a um processo decisório orientado pelo sentido de urgência e baseado tanto na capacidade como na velocidade de processamento de informações técnicas e especializadas. Por isso, empresas e instituições financeiras passam a ver o tempo diferido do processo civil e penal como sinônimo de elevação dos custos das transações econômicas, encontrando, na tendência de aumento do número de causas decididas por aplicação de normas processuais em detrimento da decisão de mérito baseada no direito substantivo, um bom argumento para justificar esse ponto de vista.

3 - No plano organizacional, além disso, o "sistema de Justiça" também não dispõe de meios materiais e técnicos para propiciar a seus integrantes a reciclagem de conhecimento e de treinamento para tornar possível a compreensão, em termos de racionalidade material, dos litígios inerentes a contextos socioeconômicoscomplexos e globalizados. $\mathrm{N}$ ão é por acaso que as corporações transnacionais, conscientes das dificuldades das instituições judiciais para lidar com o novo, interpretar normas programáticas e conhecer o próprio contexto histórico em que atuam, têm fugido dos países com tribunais ritualizadose presos a arcabouços jurídicosultrapassados, como aqueles com origem no direito romano.

Essa fuga tem três dimensões. Primeiramente, as corporações transnacionais tendem a acatar seletivamente as distintas legislações nacionais, optando por 
concentrar seus investimentos apenas nos países em cujo âmbito elas Ihes são mais favoráveis ( $N$ orth, 1990 e Pinheiro, 2000). Em segundo lugar, tendem a buscar alternativas ao processo tradicional e a se valer de instâncias alternativas especializadas, seja no âmbito governamental (por meio de autoridades administrativas independentes com poder de regulação e capacidade técnica tanto para apreciar litígios complexos como para aplicar sanções), seja no âmbito social ( por meio de negociação, mediações e de arbitragens). Por fim, tendem a acabar criando muitas das regras de que necessitam e a estabelecer mecanismos de autoresolução dos conflitos. Para as corporações transnacionais, as vantagens dessas estratégicas são inúmeras. As discussões podem ser mais rápidas e objetivas. Códigos ultrapassad os e linguagens empoladas podem ser substituídos por regras e ritos definidos pragmaticamente fora de intermediação do Estado. E as intervenções de operadoresjurídicos sem formação especializada para compreender problemas técnicos podem ser evitados. Com isso, economiza-se de tempo, 0 que faz com que essa combinação entre rapidez decisória, simplificação processual e baixo custo seja convertida no padrão básico de avaliação dos procedimentos públicose privados de resolução dos conflitos - padrão esse no qual os mecanismos extrajudiciais se destacam por uma eficiência e objetividade que os tribunais não têm como assegurar.

4 - Em termosfuncionais, como foi concebido com a prerrogativa exclusiva de aplicar o direito positivo, sob a forma de uma ordem jurídica postulada como coerente e livre de lacunas ou antinomias, o monopólio do "sistema de J ustiça" vem sendo desafiado pela expansão de ordens normativas e práticas jurídicas que, quando não negam aos órgãos judiciais do Estado a exclusividade do exercício da função de dirimir conflitos de interesses, modificam drasticamente o conceito tradicional de jurisdição. São direitos autônomos e semi-autônomos, com regras, procedimentos e recursos próprios, entreabrindo a coexistência - ora sincrônica, ora conflitante - de diferentes normatividades (Santos, 1995). N o âmbito econômico, é esse o caso da Lex M ercatoria (o corpo autônomo de práticas, regras, códigos de conduta, cláusulas contratuais, termos padronizados e princípios mercantis constituído pela comunidade empresarial para autodisciplinar suas atividades em escala internacional e propiciar critérios, métodos e procedimentos para a resolução de eventuais conflitos) e do Direito da Produção (o conjunto de normas técnicas formuladas para atender às exigências de padrões mínimos de qualidade, transporte e segurança dos bens e serviços em circulação no mercado transnacionalizado, de especificação de seus componentes, certificação da origem de suas matérias-primas, de contabilização e controle de seus custos etc.).

A partir dessa perspectiva, o pluralismo jurídico resulta em termos infraestatais, no advento de justiças técnico-profissionais constituídas à margem da jurisdição convencional e de justiças não-profissionais e informais (as comunitárias, por exemplo), ambas operadas basicamente com critérios de racionalidade material e circunscrevendo sua atuação a conflitos intragrupos, intracomunidades e intra- 
classes; e, ao nível supra-estatal, na proliferação de foros descentralizados de negociação e a multiplicação deórgãos técnico-normativos - como o I nternati onal A ccounting Standards Committe e a Internet Corporation for A ssigned $\mathrm{N}$ orms and $\mathrm{N}$ umbers - criados para unificar normas contábeis, fixar parâmetros, homologar pesquisas, dar pareceres e promover arbitragens. Atualmente, a resolução de mais de $80 \%$ dos conflitos mercantis entre empresas de médio e grande porte na economia globalizada já é feita por mediações privadas e arbitragens extrajurisdicionais. $\mathrm{N}$ os Estados $U$ nidos, a A merican A rbitration $\mathrm{A}$ ssociation, uma entidade privada, conta com 57 mil árbitros inscritos em 35 filiais. N esse país, há ainda 1.200 programas de A Iternative D isputeR esolution eA micableD i sputeR esolution, com participação de vários setores governamentais e profissionais de diferentes áreas. Sediada na França, a Chambre International du Commerce, igualmente privada, coordena mais de 750 arbitragens em trinta diferentes países, envolvendo partes de noventa distintas nacionalidades. E m Portugal, seis centros de arbitragem de conflitos de consumo já resolvem um terço dos litígios de responsabilidade extracontratual que chegam ao Judiciário (Pedroso, 2001).

5 - Diante da crescente autonomia dos diferentes setores da vida social propiciada pela globalização econômica, com suas racionalidades específicas e por vezes incompatíveis entre si levando à ampliação dos sistemas auto-organizados e auto-regulados, a Justiça foi conduzida a uma crise de identidade funcional. Por um lado, o Estado do qual faz parte, ao promulgar leis, cada vez mais é obrigado a levar em conta as variáveis internacionais para saber o que de fato pode regular e quais de suas normas serão efetivamente respeitadas. Por outro lado, os tribunais e os demais poderes do Estado também já não podem mais almejar disciplinar contextos sociais heterogêneose complexos por meio de normas ou "constituições-dirigentes" D aí as estratégias de desregulação e deslegalização que têm sido adotadas paralelamente aos programas de privatização dos monopólios públicos e à substituição das instituições governamentais de bemestar coletivo e dos mecanismos estatais de seguridade social por seguros privados, ampliando 0 intercruzamento de distintas ordens normativas.

\section{0 "sistema de J ustiça" e os processos de desregulação e deslegalização}

0 que tem estimulado a proliferação dessas estratégias é o pragmatismo de legislador. Por um lado, ele se conscientizou de que, ao tentar usar o direito positivo como instrumento de controle e direção econômica, o Estado do BemEstar dos anos de 1960 e 1970 tentou ir além do que a lógica e a racionalidade jurídica advinda da modernidade liberal permitem. Por outro, com mecanismos normativos muito simples para lidar com questões diferenciadas, e sem condições de ampliar a complexidade de seu ordenamento normativo e de seu aparato judicial ao nível equivalente de complexidade dos problemas socioeconômicos, o legislador optou pela alternativa da desregulamentação e deslegalização. Afinal, 
se quanto mais tentar controlar e dirigir menos conseguirá obter resultados satisfatórios, o que ficou evidenciado desde a crise "fiscal" e pela crise de "ingovernabilidade sistêmica" desse tipo de Estado nos anos de 1980, não resta ao legislador outra saída para preservar sua autoridade: quanto menos tentar disciplinar e intervir, menor será o risco de ser desmoralizado pela inefetividade de seu instrumental regulatório.

A conseqüência desse paradoxo tem sido uma intrincada articulação de sistemas e subsistemas internos e externos, nos planos micro e macro. Enquanto uma parte dos direitos nacionais vem sendo internacionalizada pela expansão da Lex M ercatoria e do D ireito da Produção e por suas relações com as normas emanadas dos organismos multilaterais, outra parte vem sendo esvaziada pelo crescimento de normas "privadas", no plano infranacional, na medida em que as corporações transnacionais, valendo-se do vazio normativo deixado pelas estratégias de desregulamentação e deslegalização, criam no âmbito de suas cadeias produtivas as regras de que precisam e jurisdicizam suas áreas de atuação segundo suas conveniências. A desregulamentação e a deslegalização no plano do Estado significam, desta maneira, a re-regulamentação e a relegalização no plano da sociedade (Santos, 1995) - mais precisamente, ao nível das organizações privadas capazes de, por exemplo, promover investimentos produtivos, trazer tecnologia de ponta etc.

Contribuindo assim para acelerar a crise de identidade do "sistema de Justiça", o próprio direito positivo que ele é obrigado a aplicar está com sua estrutura lógico-formal erodida. Esse direito também vê destruída a tradicional summa divisio entre o público e o privado em torno da qual foi organizado. Tem sua organicidade fragmentada por uma multiplicidade de ramos jurídicos especializados, o que provoca a ruptura da unidade conceitual da cultura jurídica de cariz normativista e privatista da magistratura. E é obrigado a responder às exigências de caráter social e econômico de modo casuístico, conforme o poder de voz, pressão e mobilização de empresas, sindicatos, O NGs etc. 0 que resta daquele ordenamento legal estruturado com base nos princípios da completude, coerência e inexistência de lacunas ou antinomias é substituído por uma legislação "descodificada", que parece caminhar na direção de diferentes redes normativas, bem como na substituição dos "interesses gerais" (ecomoo princípios "totalizadores" do sistema jurídico) por interesses corporativos conflitantes entre si. No limite, essa seria a legislação típica de um Estado semiperiférico que, não mais ocupando com exclusividade uma posição central exclusiva de controle da sociedade, é reduzido a um de seus sistemas funcionais, entre tantos outros. É o caso do Brasil.

\section{0 futuro do "sistema de J ustiça"}

Se é evidente que o J udiciário está perdendo o monopólio adjudicatório em muitos setores e matérias, o tamanho dessa perda e o futuro da instituição dependerão do modo como os tribunais irão se comportar em quatro importantes áreas. 
1 - A primeira diz respeito às conseqüências sociais da transnacional ização dos mercados, da universalização da concorrência e da concentração do poder econômico. Como esses fenômenos aprofundam a exclusão social à medida que os ganhos de produtividade são obtidos às custas da degradação salarial, da informatização da produção e do fechamento de postos de trabalho convencional, e como seu avanço provocou o surgimento de novas formas de criminalidade e ilícito econômico, exigindo respostas para as quais as instituições jurídico-judiciais não estavam preparadas para enfrentar, a simbiose entre marginalidade econômica e marginalidade social aumentou o papel do Estado, em matéria de preservação da ordem e da segurança. I sso porque, embora os "excluídos" venham perdendo condições materiais para exercer seus direitos fundamentais, eles não são dispensados dos deveres legais. Com suas prescrições normativas, o Estado os integra ao sistema jurídico em suas feições marginais, como inadimplentes, invasores etc. D iante da ampliação da desigualdade, dos bolsões de miséria, da criminalidade e da propensão à desobediência coletiva por parte de alguns grupos situados na economia informal (perueiros, camelôs, sacoleiros etc.), o Estado tem reforçado o caráter punitivo-repressivo das leis penais. Enquanto no âmbito dos direitos econômico e trabalhista vive-se um período de "flexibilização" e desregulação, no direito penal registra-se uma crescente definição de novos tipos penais, muitas vezes justificadas em nome de combate ao terrorismo, ao crime organizado, às operações de lavagem de dinheiro e à imigração ilegal; o enfraquecimento dos princípios da legalidade e da tipicidade, por meio do recurso a normas com "textura" aberta; a ampliação do rigor de penas já cominadas e da severidade das sanções; a aplicação quase irrestrita da pena de prisão; o encurtamento das fases de investigação criminal e instrução processual e a inversão do ônus da prova, com o comprometimento das garantias legais.

2 - A segunda área diz respeito às conseqüências do desequilíbrio dos poderes provocado pela expansão do Estado do Bem-Estar, nos anos de 1960 e 1970, e pela relativização de sua soberania na da década de 1980, com o avanço da globalização. Se, num primeiro momento, em resposta a pressões sociais, 0 Executivo avocou a titularidade da iniciativa legislativa, publicizando o direito privado, administrativizando o direito público e tecnicizando a política, num segundo momento o conflito de competências entre esse poder e o L egislativo levou a J ustiça a ser acionada como instância capaz de promover o desempate institucional e superar a paralisia decisória. Como juízes e promotores têm de decidir com base no ordenamento jurídico e nos limites estritos dos autos os casos que Ihes são apresentados, essa obrigação ganha relevância em face das já mencionadas transformações em andamento nesse mesmo ordenamento. Seja por causa do conflito de competências entre os três Poderes, seja porque a J ustiça e o MP sempre têm de atuar num patamar de complexidade técnico-jurídico maior do que a do Legislativo e do Executivo, seja por causa da resistência de determinados setores sociais aos processos de desregulamentação e deslegal ização, 
o fato é que, quanto mais cambiante for esse cenário, mais os tribunais serão levados ao centro das discussões políticas, mais terão de assumir papéis inéditos de gestor de conflitos e mais dificuldades enfrentarão para decidir - um fenômeno disfuncional na economia globalizada, em cujo âmbito os protagonistas preferem concentrar seus investimentos em países sem tribunais congestionados, com ritos processuais simples, transparentes e rápidos.

3 - A terceira área é a das obrigações contratuais e diz respeito à distinção que o Banco C entral na gestão do PT tem feito entre o que chama de "sistema judicial eficaz" e "sistema judicial pró-devedor" (BC, 2003). Pela pesquisa de opinião mais confiável no âmbito da magistratura, a corporação teria optado pelo segundo modelo. Conforme o I desp, 78,8\%dos juízes brasileiros consideram que, mais importante do que respeitar contratos, "é atender às necessidades sociais" (Sadek e Arantes, 1994 e Pinheiro, 2000). Essa opção favorece cidadãos e empresas em dificuldades financeiras, é justificável no plano moral e encontra fundamento legal no artigo 1이 da Constituição de 1988, que trata dos princípios fundamentais e consagra valores como dignidade humana e direito ao trabalho eà livre iniciativa. Contudo, ela tem conseqüências macroeconômicas importantes, pois os investidores tendem a sentir-se tão mais seguros quanto maior é o coeficiente de certeza jurídica dos países onde aplicam seus recursos (World Bank, 2001). Como já foi dito, isso exige o reconhecimento da propriedade privada, o cumprimento dos contratos, a proteção jurídica dos créditos e o estabelecimento das providências legais a serem tomadas no caso da impossibilidade de sua cobrança, além de tribunais rápidos e capazes de compensar, em termos econômicose em termos de segurança jurídica, a rejeição a outras formas de resolução de litígios. 0 jogo de mercado, como se vê, é incompatível com um "sistema judicial pró-devedor", independentemente dos argumentos morais usados pela magistratura para justificar sua opção pelo social. N a lógica do mercado, quando os tribunais são previsíveis, rápidos e “imparciais" , os custos indiretos da infra-estrutura judicial nas transações econômicas tendem a serem baixos, constituindo-se em fator de atração de capitais e negócios. I nversamente, quando a J ustiça é incapaz de fixar jurisprudência uniforme e tomar decisões previsíveis, ela gera custos adicionais que são transferidos ao preço dos empréstimos, por meio das taxas de risco. D ecisões de investir ou de liberar créditos, nesta perspectiva, têm relação direta com a segurança que os investidores sentem nas formas de encaminhamento e de resolução de eventuais problemas jurídicos envolvendo seus recursos ou os tomadores de seus empréstimos. Q uando a confiança é baixa e os resultados das transações econômicas não são nem seguros e previsíveis, para se proteger os investidores adicionam ao montante do investimento um valor de risco, antecipando-se às dificuldades legais e judiciais que poderão vir a enfrentar. Q uando instituições financeiras têm dificuldades para retomar imóveis dados como garantia em financiamentos imobiliários e concessionários de serviços públicos não recebem a tarifa real acertada para o período de concessão, elas deixam de conceder esse tipo de empréstimo e de investir, respectivamente. 
4 - A quarta área de atuação diz respeito aos tradicionais problemas de justiça "corretiva" e de ampliação do acesso aos tribunais. Foi para enfrentar esses problemas que, nas duas últimas décadas, o Judiciário procurou se "desoficializar" por meio de juizados especiais para as pequenas causas - os litígios de massa, rotineiros, com pequeno valor material e já jurisprudencializados. E mbora tenham a aparência de justiça de segunda classe para cidadãos de segunda classe, numa sociedade como a brasileira não se pode subestimar a contribuição desses juizados para viabilizar o acesso de contingentes expressivos da população aos tribunais. Tanto isso é verdade que, em 2002, seu primeiro ano de funcionamento, os juizados especiais federais receberam 362.191 ações, tendo sido capazes de julgar apenas 35\% delas (Valor Econômico, 15/ 4/ 03). O corre, porém, que a perversa distribuição de renda e as graves distorções por ela geradas levaram muitas matérias no âmbito da "justiça comutativa" a serem contaminadas por conflitos distributivos - o que, por conseqüência, converte "simples" questões triviais de direito positivo em questões de caráter inequivocamente político.

Essa contaminação tem sido evidenciada, algumas vezes, em matérias de interesse da maioria esmagadora da população, tais como seguro-saúde, mensalidade escolar etc. $O$ utras vezes, tem sido explicitada pelas próprias dissensões no âmbito da magistratura, sob a forma de movimentos de "juízes para a democracia", juízes favoráveis ao "direito alternativo" e juízes só preocupados com a preservação de vantagens funcionais. Diversamente destes últimos, os dois primeiros revelam consciência de que a ruptura da unidade do ordenamento jurídico, ao provocar um significativo aumento das possibilidades de escolha e decisão, abriu caminho para a politização da categoria. M as divergem quanto à orientação política a ser adotada, estimulando o retorno ao debate do tradicional problema relativo ao al cance e aos limites da hermenêutica jurídica. E m contextos socioeconômicos estigmatizados por dualismos profundos e em contextos jurídicos fragmentados por normas contraditórias e fracamente articuladas por princípios gerais muito abertos, de que modo - eis o eixo central do debate - a interpretação poderia ser resumida a um simples ato de conhecimento (e não de decisão, ou seja, não-política) e de descrição de normas (e não de criação)?

A primeira grande dúvida, portanto, é saber como o "sistema de Justiça" executará esses dois papéis conflitantes - um, de natureza punitiva, aplicável sobre os segmentos economicamente marginalizados e que lhe é imposto pelo caráter repressivo do novo arcabouço das leis penais advindas em nome do combate ao crime organizado; outro, de natureza distributiva, o que implica, além de vontade política, a adoção de critérios compensatórios e protetores em favor desses mesmos segmentos, tendo em vista a consecução de padrões mínimos de eqüidade e de coesão social.

A segunda grande dúvida é saber se os juízes têm consciência do alcance dessa contradição. $E$, também, se têm ciência de que a superação dela exige uma discussão preliminar sobre a democratização da instituição - sob a forma, por 
exemplo, de "controles" mais efetivos, como a reivindicação dosjuízes de primeiro grau de contar com representantes nos "órgãos especiais" dos tribunais. Afinal, como pode almejar ser o depositário da legitimidade democrática um Poder em que o esprit decorps de seus integrantes esvazia aos mecanismos de autofiscal ização e auto controle, levando a uma perigosa diluição de responsabilidades? U m Poder em que a el evada auto-representação que seus integrantes fazem de si pró prios se choca com a imagem de ineficiência, inépcia, a opacidade e a inacessibilidade com que é visto pelos usuários de seus serviços? Enfim, um poder internamente coeso e relativamente homogêneo, mas socialmente isolado e avesso a discutir seus problemas de forma aberta, que insiste em se apresentar como o único guardião dos valores da justiça e da invulnerabilidade perante as tentações do dinheiro e que, na maioria das vezes, exime-se de responder a cobranças por desqualificar a pri ori seus críticos, considerando-os "juridicamente desinformados"?

$E m$ termos mais objetivos: se é certo que quando enfrentam o Executivo e - Legislativo os tribunais brasileiros tendem a ser acusados de não ser uma instituição democrática, pois seu poder não deriva das urnas, não seria necessário então reformular os mecanismos de responsabilização disciplinar e legal da magistratura para refutar essa acusação? É ilustrativa, nesse sentido, a resposta dada por Perfecto I bañez, do Tribunal Constitucional espanhol. "Se do que se trata é alcançar o máximo grau possível de racionalização do exercício do poder, de todas as expressões de poder estatal", diz ele, "a consciência da indubitável relevância adquirida por tais efeitos pela independência judicial e da necessidade de fazê-la efetiva frente a todos deve ser combinada com um eficaz funcionamento dos dispositivos legais de controle (a rigorosa motivação das sentenças, entre eles) e uma ágil atuação dos mecanismos estatutários de responsabilidade [...]. Trata-se de alcançar um difícil e delicado equilíbrio no qual a dimensão cultural (da magistratura), sempre mencionada e tão descuidada, exerce um papel essencial" (I bañez, 1995, p 12).

Por isso, a terceira dúvida é saber se os juízes e promotores brasileiros, neste momento de massificação da carreira, de desvalorização social, profissional e simbólica da corporação e de "midiatização" das atividades judiciais, terão a sensibilidade e a mente alargada para extrair as lições desse debate. O u seja:

- se terão consciência de que a Justiça, por ser serviço público, está sujeita a restrições orçamentárias, motivo pelo qual sua modernização não pode ser confundida como sinônimo de construção de prédios e aquisição de computadores que jamais são usados em rede;

- se saberão adaptar à nova realidade socioeconômica vel has práticas administrativas e uma cultura técnico-profissional assentadas em princípios tornados anacrônicos pelo financiamento do capital, pela reestruturação produtiva e pela metamorfose do próprio direito, com a crescente convergência dos institutos, categorias e procedimentos da ci vil law aos da common law; 
- se terão a percepção para descobrir que as reformas processuais, por serem sempre concebidas por operadores de direito com base nos recursos oferecidos pela dogmática jurídica, jamais conseguem mudar estruturalmente 0 funcionamento da Justiça, o que só seria possível se a modernização da instituição fosse encarada como processo multidisciplinar, cujo sucesso depende da colaboração de profissionais de diferentes áreas fora do universo jurídico;

- se conseguirão reformular os mecanismos de seleção dos novos juízes e promotores, que desprezam a aptidão da função adjudicatória com base numa cultura de cidadania, limitando-se a avaliar os conhecimentos técnicolegais dos candidatos e valorizando uma cultura burocrática, o que é compatível com o papel do juiz-executor e do juiz-delegado, mas que não se adequam às complexas questões hoje levadas aos tribunais.

\section{C onclusão}

Se nas fases rotineiras da sociedade o conhecimento cotidiano, organizacional e funcional é suficiente para que as instituições saibam determinar as diferenças entre o certo e o errado, o novo e o anacrônico, o bom e o ruim, no período de transformações intensas e radicais atual, essas distinções ficam difíceis de serem reconhecidas e as incertezas se multiplicam (Santos et al. 1996). N essas situações, por isso mesmo, as instituições são obrigadas a reformular suas regras cognitivas e a rever, aprofundar e refinar seus mecanismos de aprendizagem, para conseguir neutralizar riscos, poder se adequar aos novos ventos e até garantir as condições de sobrevivência.

É a partir dessa aprendizagem que juízes e promotores podem conscientizar-se da encruzilhada em que hoje se encontram suas instituições. Por um lado, e este é um juízo de fato, o "sistema de J ustiça" faz parte de um Estado cuja capacidade de iniciativa legislativa, autonomia decisória e base tributário-orçamentária tem sido posta em xeque pela transnacionalização dos mercados. Por outro, está situado num contexto social contraditório e explosivo, que em nada lembra aquela idéia de sociedade como uma pluralidade de cidadãos livres e encarados a partir de sua individualidade, tão comum na cultura jurídica privatista; um contexto em que a cidadania, quando não é excluída e condenada ao universo da informalidade, é integrada e submetida ao "moinho satânico" do capital globalizado, com todos os custos sociais, políticos e morais que isso acarreta.

Acionada pelos "excluídos" para dirimir conflitos que afetam o processo de apropriação das riquezas e distribuição eqüitativa dos benefícios sociais, mas desprezada por muitos setores "incluídos" na economia transnacionalizada, que tendem a elaborar as próprias normas, ritos e mecanismos de resolução de controvérsias, o "sistema de Justiça" tem de redefinir seus espaços de atuação e forjar uma identidade funcional mais precisa. Se estão certos aqueles que afirmam não ter ele outra legitimidade a não ser a que lhe é dada por sua independência 
institucional, por sua eficiência funcional e por sua autoridade moral, essa legitimidade precisa ser permanentemente validada pela prática, no cotidiano de cada tribunal. É por isso que esse "sistema" e seus integrantes têm de mudar.

\section{Bibliografia}

ARANTES, Rogério Bastos e KERCHE, Fábio. "Judiciário e D emocracia no Brasil", em N ovos Estudos, São Paulo, Cebrap, № 58, 1999.

BAN CO CENTRAL. Sistema judicial e mercado de crédito no Brasil. N otas Técnicas no 35, Brasília, 2003.

CAM PI LO N GO, Celso Fernandes. Política, direi to e decisão judicial: uma redescrição a partir da teoria dossistemas. São Paulo, Tese de Concurso, 2000.

CAST RO, M arcos Faro. "Los Tribunales, el D erecho y la D emocracia em Brasil", em R evista Internacional de Ciências Sociales, Paris, U nesco, 1996.

D WO RKIM , Ronald. "J uízes políticos e democracia”, em O Estado deS. Paulo, 1997, pp. 20-23.

FIT ZPATRICK, Peter. "The Rise and Rise of I nformalism", em I nformal J ustice, Roger M atthews (org.), L ondon, Sage, 1988.

IBÁNEZ, Perfecto Andrés. "El Poder Judicial en M omentos Difíciles", em Claves de R azón Práctica, M adrid, 1995.

IDESP. A crise do Judiciário vista pelos juízes São Paulo, Relatório de Pesquisa, M. Teresa Sadek e Rogério Bastos Arantes (orgs.), 1993.

GU ARN IERI, Carlose PED REZO LI, P. La puissancedejuger. Paris, M ichalon, 1996.

M OREIRA, Vital. A uto-R egulação Profissional e A dministração Pública. Coimbra, Almedina, 1997.

NORTH, Douglas. Institutions, institutional change and economic performance. Cambridge (M ass.), C ambridge U niversity Press, 1990.

PEDROSO, João. "O caso dos Centros de Arbitragem de Consumo", em R evista Crítica de Ciências Sociais, Coimbra, no 60, 2001.

PIN H EIRO, Armando Castellar. Judiciário e economia no Brasil. São Paulo, Sumaré, 2000.

SADEK, M. Teresa e ARANTES, Rogério Bastos "A crise do Judiciário e a visão dos juízes", R evista U SP, São Paulo, U SP, 1994.

SANTOS, Boaventura. Toward a N ew Common Sense: law, science and politics in the paradigmatc transition. London/ N ew York, Routledge, 1995.

SANTOS, Boaventura; M ARQ U ES, M aria M anuel L.; PEDROSO, J oão; FERREIRA, Pedro L. Ostribunais nas soci edades contemporâneas. Porto, Afrontamento, 1996.

SAN TOS, Wanderley Guilherme. A srazões da desordem. Rio de J aneiro, Rocco, 1993.

TATE, N eal e VALLI N D ER, Torbjörn. "The G lobal Expansion of J udicial Power, the Judicialization of Politics", em The Global Expansion of Judicial Power. N ew York, N ew York U niversity Press, 1997. 
WO RLD BANK. Building Institutions for Markets. Washington, World D evelopment Report 2002, Oxford U niversity Press, 2001.

R ESU M O - O OBJETIVo deste artigo é apontar o descompasso entre o sistema brasileiro de J ustiça e a realidade socioeconômica em que atua; discutir o fenômeno da "judicialização da vida política e econômica", mostrando como o crescente protagonismo de juízes e promotores numa sociedade tão iníqua como a brasileira torna o sistema de Justiça vulnerável a tentativas de intervenções externas; e avaliar as transformações na ordem jurídica provocadas pela globalização da economia, abrindo caminho para a perda da exclusividade dos tribunais na resolução dos conflitos.

ABTRACT - THIS PAPER has three goals. First, it points out the gap between the Brazilian system of J ustice and its social and economic enviroment. Second, it puts in debate the well known "judicialization of politics" phenomena, taking into account the increasing political and functional intervention of judges and prosecutors in such a complex and unequal society, like the Brazilian one, and identifying the effects of this performance on the autonomy of the legal system. Third, the paper comments the impact of the economic globalization on the Brazilian legal system and the subsequently rupture of the monopoly of tribunals on resolution of disputes.

J oséEduardo Faria é professor-titular da Faculdade de D ireito da U niversidade de São Paulo.

Texto recebido e aceito para publicação em 5 de junho de 2004. 